\title{
La plastía de Ralph Millard en el labio leporino. Experiencia local en 25 casos operados en 2 años
}

Dr. Rodrigo Espejo González*, Dr. Jorge Cabello Pizarro*

El drama de los niños portadores de un labio leporino es un problema que ha motivado una preocupación especial de nuestra parte, por lo difícil que es para estos pacientes (como para cualquier otro) conseguir cama en los centros quirúrgicos especializados de la capital.

Hemos tratado de solucionar en nuestro Hospital de Talca, con los escasos medios de que disponemos, esta afección que motiva una presión constante de los familiares y de la sociedad misma hacia nosotros; y que obliga a una prioridad de tratamiento sobre otras patologías, deformantes o no.

Nuestra experiencia ha sido lograda en pacientes de la séptima región, que abarca de Teno a Parral, y que frecuentemente llegan a nuestro centro quirúrgico desde apartados lugares precordilleranos o costinos, con grandes dificultades, y en la esperanza de ver solucionado su problema en forma rápida y eficaz.

Nos guía esencialmente el ánimo de demostrar la factibilidad de solucionar los problemas en forma regional, prescindiendo de los grandes centros capitalinos que deben constituir centro de enseñanza y guía, pero no centros receptores de pacientes con patología posible de resolver, con dedicación y paciencia, en la localidad misma.

\section{MATERIAL Y METODO}

Entre los años 1975 y 1977, hemos intervenido veinticinco pacientes portadores de labio leporino completo complicado, haciendo uso de la técnica descrita por Ralph Millard en 1960, y aprendida en el Hospital Manuel Arriarán en el

*Unidad de cirugía infantil Hospital César Garavagno B. Talca. período de becario en la especialidad. (Figura N." 1 .)
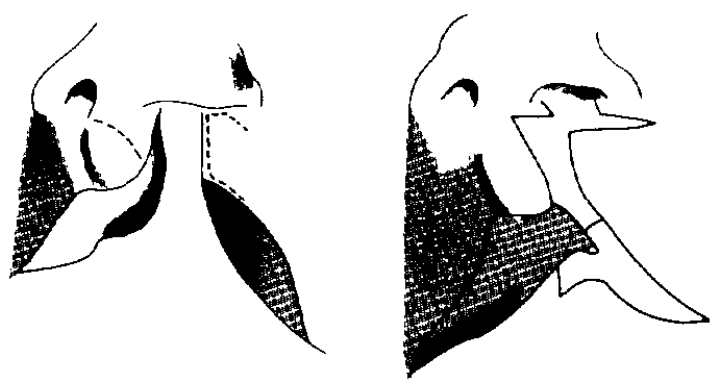

Este metodo, como fuera descrito por su autor, puede ser medido con exactitud en forma lineal, pero nos hemos acostumbrado a usarlo un poco a ojo, haciendo uso de algunas medidas básicas tomadas con un compás de punta corriente.

Se procede en primer lugar a bosquejar sobre la zona operatoria las incisiones a usar, tomando como punto de referencia el centro del arco de cupido.

Se practica una incisión de rotación, llevando a una posición normal la parte del arco de cupido que pertenece a la fosa del filtro, y separando el bermellón. Igual descenso se realiza en la pared contralateral.

El colgajo superior así formado se desliza a la columela para formar el piso del orificio nasal afectado.

El colgajo formado en la pared opuesta se desliza hacia abajo, y se intercala en la línea de unión muco-cutánea.

El cierre se realiza en dos planos. El primero, muscular, con catgut crómico 0000 , realizando en este tiempo el arreglo del bermellón, recortando 
el excedente, y adosando suavemente los bordes.

La piel se sutura con seda 00000 , retirando los puntos al $4 .^{\circ}$ día; durante este tiempo el niño se mantiene con sus manos amarradas y recibe un régimen licuado administrado directamente con jeringa, a fin de evitar en lo posible la succión.

\section{RESULTADOS Y DISCUSION}

En general, nuestros resultados estadísticos no hacen sino confirmar lo descrito en forma clásica en los textos de estudio.

Dieciséis de nuestros pacientes son de sexo masculino, y nueve, de sexo femenino, constituyendo una relación de 2:1 bastante aproximada. (Cráfico N." l.)

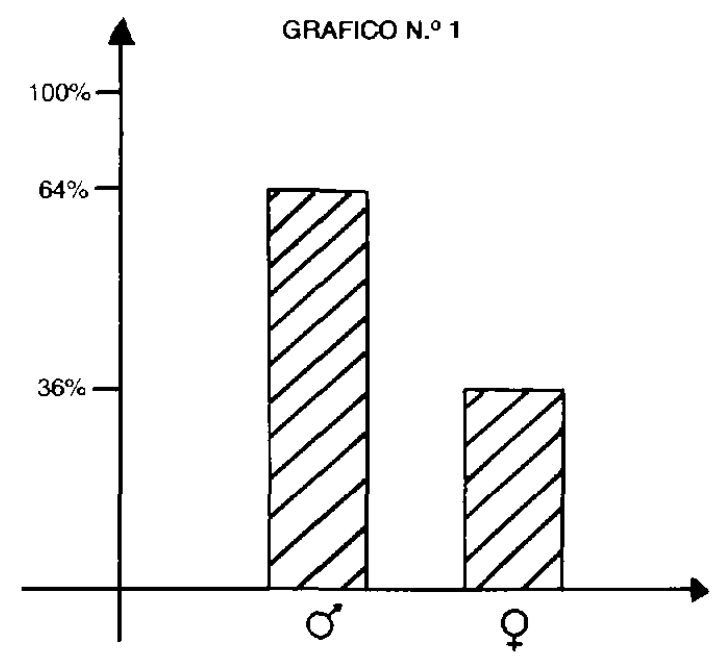

Existe además una clara predominancia de la afección sobre el lado izquierdo. De los tres casos bilaterales operados, se aplicó la plastía de Ralph Millard a un lado. En el otro lado se usó previamente la plastía de Veau. La edad de nuestros pacientes operados fluctuó entre los cinco meses y los diecinueve años. (Gráfico N. ${ }^{\circ}$ 2.)

Los resultados estéticos obtenidos con esta plastía nos parecen bastante aceptables, y no hemos intentado usar otra por parecernos que el éxito estriba en el dominio que se tenga de una técnica, y de las modificaciones que se practican a ella en pos de la perfección.

Hemos logrado así un buen resultado en la formación de la ventanilla nasal, movilizando el colgajo superior lo más atrás posible, redondeando en forma bastante aceptable el orificio con esta maniobra.

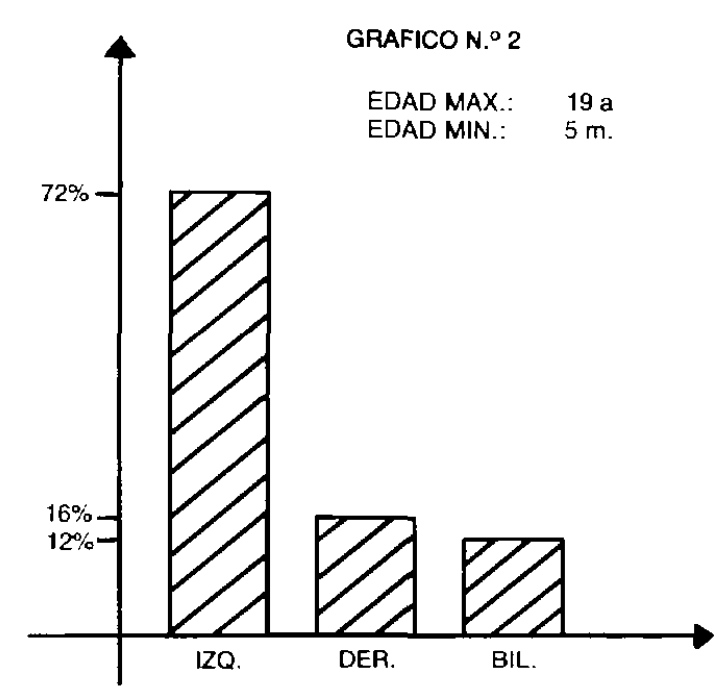

En algunos casos hemos tenido dudas en cuanto a la simetría resultante por la protrusión exagerada de la pre-maxila, pero hemos visto. como evolución natural, una regularización excelente con el transcurso del tiempo.

En los pacientes adultos que hemos intervenido, hemos obtenido buenos resultados estéticos, aun cuando en ocasiones hemos debido recurrir a intervenciones complementarias, como plastías nasales de corrección.

Los resultados, que nos han parecido más que aceptables, nos impulsaron a usar la plastía de Ralph Millard en otro tipo de malformaciones $o$ alteraciones bucales.

Una cuidadosa planificación nos llevó a la conclusión de que esta técnica sería fácilmente aplicable en los casos de macrostomía, o en aquellos en que fuera necesario el estrechamiento de la comisura labial.

El primer paciente intervenido con esta modalidad fue un adulto que, a raíz de la extirpación de labio inferior por un cáncer labial, quedó con una comisura abierta y deformada, que impedía la normal alimentación. La plastía se aplicó según la técnica descrita, y obtuvimos resultados satisfactorios.

Esto nos llevó a aplicar la plastía de Ralph Millard hacia macrostomías, secuelas de quemaduras, etc., con éxito creciente que esperamos sea motivo de una posterior comunicación.

\section{CONCLUSIONES}

De acuerdo a nuestra escasa experiencia y a los resultados obtenidos, nos permitimos recomen- 
dar la plastía de Ralph Millard como un método fácilmente aplicable, con buenos resultados estéticos, y que nos permite solucionar en forma simple y adečuada esta patología deformante, que requiere pronta atención por el bienestar psicológico de la familia y del paciente mismo.

Consideramos asimismo que esta plastía ofrece amplias posibilidades de aplicación, y que, no dando secuelas cicatriciales, puede ser usada en la reparación plástica de otras malformaciones bucales con éxito.

La dedicación que pongamos en el uso y perfeccionamiento de la técnica que elijamos para solucionar una patología tan deformante e imposible de ocultar, como es el labio leporino, nos permitirá dar una oportunidad a niños que podrán mirar con la frente y los labios en alto hacia un promisorio futuro.

\section{RESUMEN}

1. Se plantea la necesidad de solucionar en los centros regionales donde exista lu especialidad los problemas de labio leporino, evitando recurrir a los centros capitalinos, en pos de la pronta solución de esta patología deformante.

2. Se describe la técnica de Ralph Millard aplicada a veinticinco pacientes operados en el lapso de dos años en el Hospital Regional de Tulca.

3. Se analizan los resultados según sexo, edad de consulta y predominancia del lado afectado.

4. Se muestran los resultados estéticos obtenidos y analizan las modificaciones practicadas en la técnica misma.

5. Se insinúa la posibilidad de aplicar la plastía de Ralph Millard en otras malformaciones bucales, debido al facil dominio de la técnica, y a los buenos resultados estéticos obtenidos. 